\title{
Exclusively endoscopic approach for juvenile angiofibroma in an adult - a case report
}

\author{
Witold Szyfter, Mariola Popko, Małgorzata Leszczyńska, Wojciech Gawęcki \\ Department of Otolaryngology, Poznan University of Medical Science, Poland
}

Videosurgery and other miniinvasive techniques 2010; 5 (3): 107-109 DOI: $10.5114 /$ wiitm.2010.16422

\begin{abstract}
Aim: To demonstrate clinical, radiological, and diagnostic pitfalls of juvenile angiofibroma (JA) in an adult. Study design: Retrospective analysis of a case report.

Results: Juvenile angiofibroma in adults is a rare entity with only two cases reported in the literature, confirming the low prevalence of the disease. We present a case of juvenile angiofibroma in an adult that preoperatively was suspected to be a malignant disease. Effective treatment included surgical excision via an exclusively endoscopic approach.

Conclusions: Symptoms of JA in an adult may mimic a malignant process. However, in the case of unilateral epistaxis, rhinorrhea and nasal obstruction in an adult JA should be considered in the differential diagnosis.
\end{abstract}

Key words: juvenile angiofibroma, exclusively endoscopic approach

\section{Introduction}

Juvenile angiofibroma (JA), a rare tumour developing in adolescent and young adult males, accounts for $0.05-0.5 \%$ of all head and neck tumours [1]. Juvenile angiofibroma is composed of histologically benign connective and vascular tissues, and is characterised by local infiltration [2]. Although androgens and the co-existence of familial adenomatous polyposis (FAP) are thought to play an important role, the pathogenesis of JA still remains unclear [3]. Epistaxis and nasal obstruction are the most common manifestations. JAs can be a life-threatening condition, as the tumour tends to spread towards the base of the skull and intracranially.

Our knowledge of JA in adults is limited to two cases presented in the literature $[4,5]$. The purpose of this article is to report on an interesting case of $\mathrm{JA}$ in an adult patient that preoperatively was suspected to be a malignant disease. The patient was successfully treated with exclusively endoscopic surgery.

\section{Case report}

A 56-year-old male presented with a 6-month history of moderate nasal obstruction on the left side and recurrent bloody nasal discharge. Nasal endoscopy showed an uneven, livid-red mass in the left inferior nasal meatus that did not extend caudally into the nasopharynx (Figure 1).

Contrast-enhanced computed tomography (CT) revealed a $1.5 \times 2 \mathrm{~cm}$ tumour in the left inferior nasal meatus extending from the inferior nasal turbinate with no evidence of nasopharyngeal or intracranial expansion (Figure 2). The patient was selected for an explorative endoscopic biopsy to evaluate suspected malignancy. The material was sent for routine histopathology. The histological diagnosis was juvenile angiofibroma. 
The patient underwent preoperative angiographic embolization of the left maxillary artery branches to reduce intraoperative blood loss (Figure 3).

Exclusively endoscopic surgery under general anaesthesia and controlled low systolic blood pressure was performed to remove the tumour in total $[6,7]$.

Ethmoidectomy was initially done in order to better visualize the tumour, followed by a wide meatal antrostomy to reveal the posterior wall of the maxillary sinus. The inferior turbinate together with the

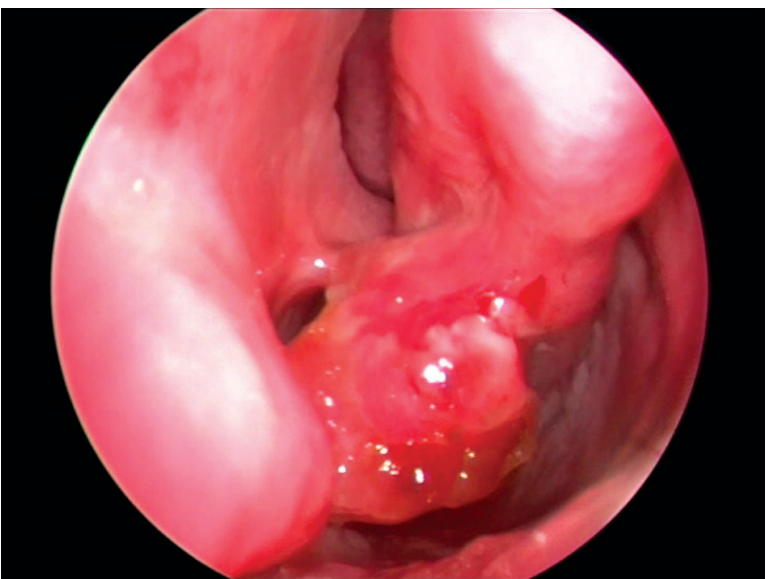

Figure 1. Endoscopic view of the left nasal cavity with significant obstruction of the inferior nasal meatus by a soft tissue mass originating from the inferior nasal turbinate

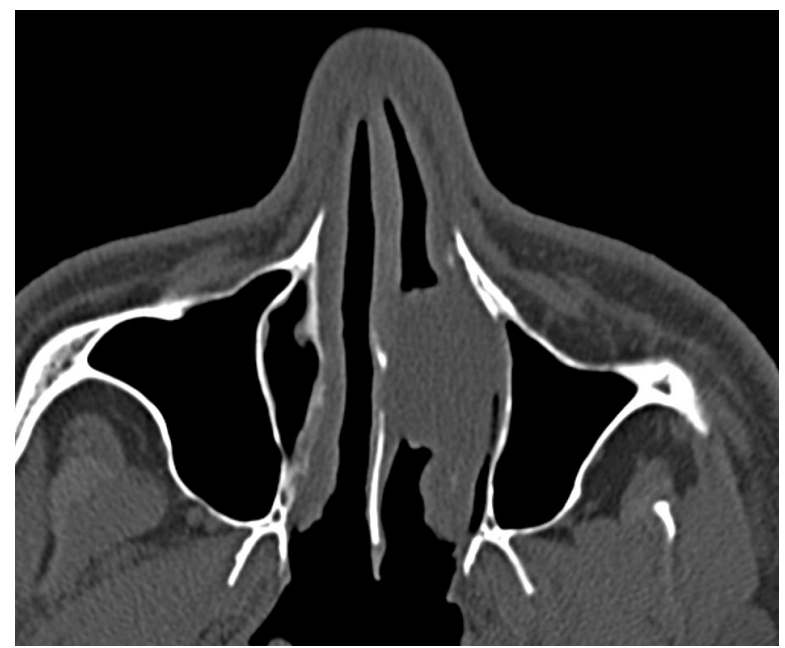

Figure 2. The axial computed tomography (CT) section of the nasal cavity and paranasal sinuses demonstrates a homogeneous soft tissue density mass within the left nasal cavity originating from the inferior nasal turbinate tumour was then resected and removed through the nasal cavity. Bleeding was controlled by coagulation and nasal packing. Nasal packing was left in place for 24 hours. Postoperative follow-up visits took place every 3 months. Endoscopic assessment of the postoperative cavity was performed at each visit, and an imaging study (CT or MRI) was done once a year. No recurrence was observed during the postoperative period of 2 years.

\section{Discussion}

Juvenile angiofibromas occur primarily in young boys. In adults it is a rare entity with only two cases reported in the literature $[4,5]$.

The primary symptoms of JA include nasal obstruction, rhinorrhea and epistaxis. Accordingly, our patient presented similar symptoms. Dulguerov et al. [9] reported that paranasal sinus neoplasms may mimic benign sinonasal disease. However, as the mass grows, paranasal sinus malignancy leads to facial pain, orbital symptoms, hard-palate mass and cranial neuropathies if the skull base is invaded. Our patient's complaints were misinterpreted as signs of a possible malignancy, assuming that unilateral bloody nasal discharge and nasal obstruction in adults generally suggest a malignant process.

Juvenile angiofibroma can be a life-threatening condition, as the epistaxis tends to be profuse and difficult to control. If we had suspected JA before the histopathology biopsy was performed, we might have opted for angiographic embolization first.

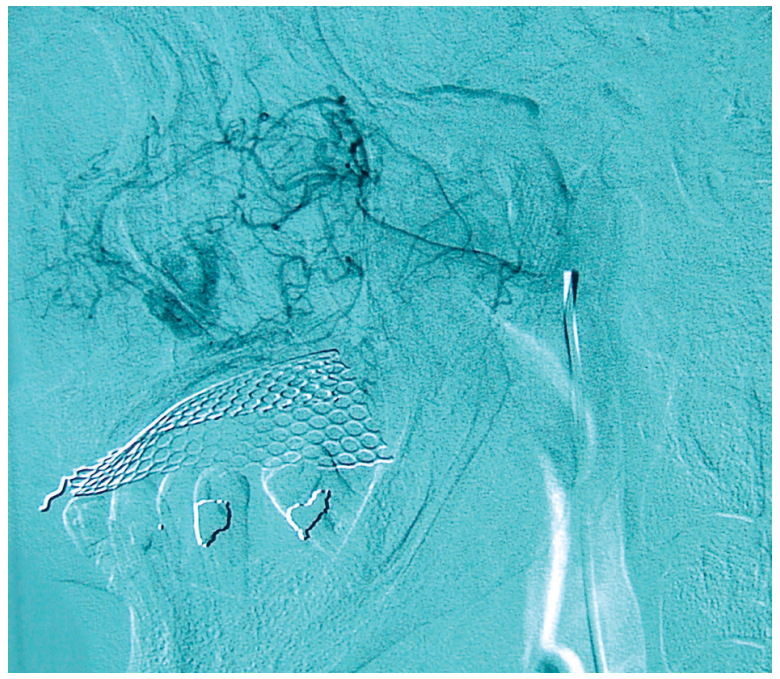

Figure 3. Angiography of the left maxillary artery supplying the JA 
Juvenile angiofibroma on CT scan is multilobular and enhances intensively post-contrast. It tends to show bone remodelling rather than aggressive destruction, although the tumour may directly invade bone. In contrast, according to Schuknecht et al. [10] computed tomography images of sinonasal malignancy typically demonstrate bone destruction, which did not correspond with the radiological findings in our case. However, the size of the tumour in our case allowed the assumption of malignancy at the early stage.

Juvenile angiofibroma develops in the posterolateral wall of the nasal cavity near the superior border of the sphenopalatine foramen. The tumour can extend medially to the nasal cavities or the nasophar$\mathrm{ynx}$ and laterally to the pterygopalatine fossa and the infratemporal fossa. From the pterygopalatine fossa, the tumour may further extend into the orbit through the inferior orbital fissure. From the infratemporal fossa, the tumour may grow upwards through the base of the pterygoid process into the area between the foramen ovale, rotundum and lacerum, reaching the middle cranial fossa. Juvenile angiofibroma can erode the lateral and posterior wall of the sphenoid sinus and extend as far as the pituitary gland [11]. Although the localization of the JA is said to be highly pathognomonic, the preoperative radiological evaluation in our case contradicted the literature and did not lead to the correct diagnosis. Interestingly, the tumour in our patient was limited to the inferior nasal meatus, sustaining the suspicion of malignancy.

In addition, JAs are often large at the time of presentation in adolescent boys. After several months of unspecific symptoms JA may extend into the nasopharynx, paranasal sinuses and the middle cranial fossa. In our case, the JA was limited in size despite the long period of presented symptoms (6 months). We therefore assume that androgens may play an important role in the slow rate of JA growth in adults.

\section{Conclusions}

1. Juvenile angiofibroma in an adult is a rare condition.

2. Symptoms and signs of JA in an adult may mimic a malignant process.

3. In the case of unilateral bloody nasal discharge, rhinorrhea and nasal obstruction in an adult, JA should be considered in the differential diagnosis.

4. It is essential to be aware of uncommon localization of JA in adults in CT evaluation.

\section{References}

1. Gullane PJ, Davidson J, O’Dwyer T, Forte V. Juvenile angiofibroma: review of the literature and a case series report. Laryngoscope 1992; 102: 928-33.

2. Paris J, Guellfuci B, Moulin G. Diagnosis and treatment of juvenile nasopharyngeal angiofibroma. Eur Arch Otorhinolaryngol 2001; 258: 120-4.

3. Schick B, Rippel C, Brunner C. Numerical sex chromosome aberrations in juvenile angiofibromas: genetic evidence for an androgen-dependent tumor? Oncol Rep 2003; 10: 1251-5.

4. Aduba O. Juvenile nasopharyngeal angiofibroma in an adult male. Ear Nose Throat J 1984; 63: 196-7.

5. Łukomski M, Danilewicz M, Pajor A. Juvenile angiofibroma in adults. Otolaryngol Pol 2008; 62: 20-6.

6. Szyfter W, Popko M, Borucki Ł. Outcomes of endoscopic surgery, endoscopic-assisted surgery and open surgery in the treatment of juvenile nasopharyngeal surgery. Videosurgery and other miniinvasive techniques 2009; 4: 138-46.

7. Borucki Ł, Szyfter W, Wróbel M. Endoskopia pęczka twarzowosłuchowego w kącie mostowo-móżdżkowym; badania anatomiczne. Wideochirurgia i inne techniki małoinwazyjne 2007; 2: 34-8.

8. Niemczyk K, Siwek M, Sobczak A, Brzeziński R. Dacryocystorhinostomia; metoda mikrochirurgii wewnątrznosowej. Videosurgery and other miniinvasive techniques 2006; 1: 125-8.

9. Dulguerov P, Jacobson MS, Allal AS, et al. Nasal and paranasal sinus carcinoma: are we making a progress? Cancer 2001; 92: 3012.

10. Schuknecht B, Simmen D. State of the art. Diagnostic imaging of paranasal sinus diseases. Laryngorhinootologie 2002; 81:126-46.

11. Douglas R, Wormald PJ. Endoscopic surgery for juvenile nasopharyngeal angiofibroma: where are the limits? Curr Opin Otolaryngol Head Neck Surg 2006; 14: 1-5. 